\section{Advantages and Disadvantages of Asynchronous Online Extension Programming for Delivering Master Producer Content}

\author{
S. Christopher Marble ${ }^{1,4}$, Amy Fulcher ${ }^{2,5,7}$, and John Toman ${ }^{3,6}$
}

ADDITIONAL INDEX WORDs. continuing education, distance education, e-learning, nursery production, professional development

Summary. Budget reductions for the Cooperative Extension Service have made traditional extension programming (face-to-face, live programming) difficult for extension professionals. Attending traditional extension programming can also prove to be challenging for industry practitioners due to the need to delay or reschedule work activities and the need to travel to participate. The Tennessee Master Nursery Producer program (TMNP) is a professional development extension program designed to enhance the sustainability of the Tennessee nursery crops industry. The TMNP was first offered as a traditional extension program in 2012. Although the program was successful, it demanded substantial time from faculty and staff to coordinate the program, prepare presentations, and travel. Recurring travel expenses required a significant financial commitment from both extension personnel and participants. An asynchronous online program was developed to address these challenges and to increase accessibility, exploit the economies of scale, and standardize curriculum. The objective of this article is to describe the advantages and disadvantages that were identified offering nursery production subject matter as a traditional live classroom and subsequently as an asynchronous online program in terms of development cost, administrative and technological requirements, and economic impacts.

We thank the Tennessee Department of Agriculture for financial support received to develop the Tennessee Master Nursery Producer Program, and Richard Karel, Whitney Yeary, and Olivia Martin for technical assistance as well as the speakers who contributed to the live Tennessee Master Nursery Producer program: Karla Addesso, Douglas Airhart, Matthew Chappell, Donna Fare, Mark Halcomb, Frank Hale, Gray Haun, Brian Jackson, Anthony V. LeBude, Jason Oliver, Jim Owen, Marco Palma, Alice Rhea, Jane Howell Starnes, Sarah A. White, Alan Windham, and Jean Williams-Woodward. We also wish to extend sincere gratitude to Nastaran B. Jahromi and Brian Pearson for providing a thorough internal review of this manuscript and to external reviewers whose insight greatly strengthened the manuscript.

This paper results from the workshop "Online Learning and Big Data in Horticulture: New Insights and Directions" held 4 Aug. 2015 at the ASHS Annual Conference, New Orleans, LA, and sponsored by the Computer Applications in Horticulture (COMP) Working Group.

Mention of a trademark, proprietary product, or vendor does not constitute a guarantee or warranty of the product by the authors or their respective institutions and does not imply their approval to the exclusion of other products or vendors that may also be suitable.

${ }^{1}$ Department of Environmental Horticulture, University of Florida, Mid-Florida Research and Education Center, 2725 South Binion Road, Apopka, FL 32703

${ }^{2}$ Department of Plant Sciences, University of Tennessee, 2431 Joe Johnson Drive, Ellington Plant Science Building, Room 252, Knoxville, TN 37996

${ }^{3}$ University of Tennessee Extension, 212 Morgan Hall, Room D4, Knoxville, TN 37996

${ }^{4}$ Assistant Professor (former postdoctoral scholar, University of Tennessee)

${ }^{5}$ Associate Professor

${ }^{6}$ Information Technology Specialist III

${ }^{7}$ Corresponding author. E-mail: afulcher@utk.edu.

doi: 10.21273/HORTTECH03410-16 programming attendance decreased as nurseries reduced many expenses including travel and staffing (A. Fulcher, unpublished data). Managers and crew leaders who heretofore had the time to attend programs took on additional production responsibilities.

During economic recessions, when grower needs are greatest, extension programming is less able to meet those needs through traditional programming due to budget cuts and fewer stakeholders attending muchneeded programming. In an effort to solve this paradox while extension budgets decline, investment in information technology (IT) has generally risen (Wells, 2004). Increased access to continuous learning, distance education, and asynchronous education through the use of technology was a directive of the National Association of State Universities and Land-Grant Colleges commission (The Engaged Institution, 1999). Universities, as well as regional and county extension facilities, have continued to improve the communication infrastructure in support of distance learning for credit courses and to facilitate staff training and communication with the main campus. These technologies can create cost-effective opportunities for disseminating information to extension audiences and contain the infrastructure necessary for complex ongoing programs.

The TMNP program is a professional development extension program designed to enhance the sustainability of the Tennessee nursery crops industry and position them for long-term national and international competition. The TMNP was first offered as a traditional extension program consisting of $4 \mathrm{~h}$ of class per week for a 6-week period in 2012. Exit and subsequent follow-up evaluations with attendees document that the program was successful; however, faculty and staff noted it demanded a substantial amount of time to coordinate the program, prepare presentations, and time needed to travel to the class location, $\approx 2.5 \mathrm{~h}$ from the main campus in Knoxville, TN. Moreover, given that out-of-state subject matter experts presented a substantial portion of the program, financial support was needed for travel expenses. Likewise, weekly travel expense was a substantial cost incurred by participants. Nursery growers in remote locations were hampered by the 
time and expense of travel. Therefore, an asynchronous online program was developed to help address these challenges, as well as increase accessibility, exploit the economies of scale, and standardize curriculum. The objective of this article is to describe the advantages and disadvantages that were identified offering a master nursery producer program as a traditional live classroom and subsequently as an asynchronous online program. For more information on developing the online program, please consult the companion article (Marble et al., 2016).

\section{Materials and methods}

Advantages. Advantages of an asynchronous online format include the one-time development of an organizational structure for program scheduling; one-time lecture development and recording; and multiple offerings of certification material. Conditional access is a major advantage of an online program for the administrator as well as participants. The conditions ensure that participants complete required items and in the required order. Because conditional access routes participants through the modules in a prescribed order, the information is provided in a stepwise fashion, building on the previous modules' content to enhance learning; e.g., the second irrigation module cannot be accessed until the first irrigation module is complete and the quiz score for the first module meets the minimum requirement. Not only are modules conditional, but so are pre- and posttests, registration and impact questionnaires, and other required forms.

A significant advantage of offering an asynchronous online Master Producer program is the automation of questionnaires and certificates. Questionnaires provide valuable insight for extension professionals. For the TMNP, a comprehensive registration questionnaire functions as an ongoing needs assessment of the Tennessee nursery production industry and an impact questionnaire captures economic, environmental, and other impacts of the program. Although this information can be captured in a live face-to-face program, participants may not answer questionnaires at all or answer them completely, which makes it difficult to fully assess the impact of a program. With an online program, certificates are automatically issued when all conditions are met, allowing participants the convenience of printing their own certificates and freeing program administrators from that responsibility.

A tremendous advantage for growers and extension professionals is the scheduling flexibility afforded by an asynchronous online program compared with a traditional live program (Richards et al., 2012). Students can begin the course at any time and many modules can be completed during poor weather conditions or when a lull in workload is reached unexpectedly, and evenings and weekends are also options for completing program content. Students have complete flexibility as to when they choose to login and work on the program including not having to wait to begin the program due to continuous enrollment.

Disadvantages. An asynchronous online program is time intensive to develop, leading to high initial costs (Marble et al., 2016). Because the information is presented without opportunity to clarify, offer additional explanation, or immediately answer questions as would be the case with a live class, content must be painstakingly prepared and inspected so the images and text on each slide are explicit and supported by the narration, leaving no room for ambiguity or misinterpretation. In support of this detailed level of content development, either many committee members are needed representing the disciplines included or a uniquely qualified individual must be employed. An e-learning specialist or other individual with experience creating online learning modules is necessary as is a professional narrator and university capacity to host and maintain an online program and e-payment system. A support position in IT is required to assist participants with technical difficulties. The program content can become dated if time and/or funds are not prioritized to maintain current content. This can be especially important if pesticide recommendations are included in content.

Potential constraints for participants in an online program include the need for a reasonably new computer/operating system and computer skills. In the case of the TMNP, Adobe ${ }^{\circledR}$ Reader and Flash Player (both Adobe Systems, San
Jose, CA) are needed. Growers in the online TMNP do not directly interact with nationally recognized experts. Therefore, students may not be exposed to the very latest information in a particular field or have the benefit of having an expert immediately address any specific question they have. Additionally, the nature of student camaraderie is very different. Unlike the live program, there is no student interaction. Participants do not have the external positive reinforcement of seeing fellow classmates each week, or the negative incentive of peer scrutiny if a class is missed. Peer-to-peer learning opportunities are not available to participants. Likewise, the students and program coordinator do not interact in person, but rather online or by phone when questions arise.

\section{Results and discussion}

Developing the online program required $1721 \mathrm{~h}$ and $\$ 0$ travel expenses, while coordinating the traditional live program required $230 \mathrm{~h}$ and $\$ 2509$ in travel expenses. About $6.5 \times$ more hours were needed to develop the online program than to conduct the live program; however, this calculation disregards speaker preparation time for the live class. The online TMNP required $35.1 \mathrm{~h}$ per student, whereas the live program was $6.1 \mathrm{~h}$ per student through June 2016. It is anticipated that the economies of scale will decrease the per student costs the longer the asynchronous program is available. It was critical to the success of the program to offer IT support for technical difficulties, but it only accounted for $1 \%$ of the e-learning specialist's time toward the project, $4.0 \mathrm{~h}$ (Marble et al., 2016), a manageable expense as the program continues.

An additional cost that will be incurred with an online program is the long-term management and costs associated with website management (ongoing technical support and website hosting) and the need to periodically update program content. Uniform resource locators must be updated periodically to prevent broken links. Software used during program development could also become outdated, obsolete, or no longer be available and require modification to a new platform, which could be time consuming. The need for updating or revising program 
content will be highly dependent on subject matter. Modules addressing overwintering or nursery site selection contain information that is highly unlikely to change. For the TMNP, modules pertaining to pests or pesticide recommendations will need to be updated more frequently than other modules due to invasive species, lack of registration renewal, and development of pesticide resistance, and /or registration of new pesticides. In the TMNP, the pest management modules are the most highly ranked as valuable by growers in the impact questionnaire by $2.5: 1$, further emphasizing the need to update this content.

Participant cost is another factor to consider when offering an asynchronous online program. When the online TMNP was developed, the registration fee was established at the same level as the traditional live program, $\$ 125$. Additional costs for attendance at the live program included $\$ 152$ for an average 47 -mile $(75.6 \mathrm{~km})$ round trip using the federal mileage rate of $\$ 0.54 / \mathrm{mile}(\$ 0.336 / \mathrm{km})$. Once at the location of the live program in McMinnville, TN, growers spent $24 \mathrm{~h}$ of time plus travel for an average time commitment of $30.3 \mathrm{~h}$ per grower.

For the online program, growers spent an average of 75 min per module (and quiz) for a total classroom time of $26.3 \mathrm{~h}$ for all $2 \mathrm{l}$ modules. The opportunity cost of participating in the program was reduced by $\approx 13 \%$ because there was no travel time. Growers routinely commented that they appreciated the flexibility to participate in the program when it was convenient for them. Growers reported working on the program when it was too dark to do field work and during very cold and wet periods that prevented outdoor work. Many growers completed modules on the weekend or late in the evening. Both groups had study time that record keeping did not include.

OUTPUTS AND OUTCOMES OF A TRADITIONAL LIVE PROGRAM AND AN ONLINE ASYNCHRONOUS PROGRAM. Results of the asynchronous pre- and posttests have been enlightening. While most growers in the online program have 20 years of experience, as determined from the registration questionnaire, the pretest score was $58 \%$ indicating there is content in the program the participants had not previously mastered. The posttest scores, average of $89 \%$, indicate that a substantial level of learning occurs. Both pre- and posttests are automatically graded and averages calculated automatically. Previously, with the traditional live program, a pretest was not offered, though this would have been possible by requesting speakers submit questions to the coordinator in advance of the class.

ESTIMATED ECONOMIC IMPACTS. After completing the live program, growers estimated they would save $\$ 4272$ by putting into practice information they acquired in the TMNP. At the conclusion of the online program, growers estimated they would save $\$ 7406$ as a result of new knowledge gained and practices changed and $\$ 6612$ due to an increase in plant quality as a result of participating in the TMNP online program for a total of $\$ 14,019$. Growers responded they would have repeated annual savings estimated at $10 \%$ due to a reduction in reoccurring expenses, such as reducing the amount of fertilizer or pesticides they will apply.

Identifying potential economic benefits from asynchronous programs is important to maximize utility, accurately market the program, and for making informed decisions about future extension program development. Some causes are likely curriculum based and others are likely based on the nature of online asynchronous programming. With the online program, the program coordinator had complete control of the curriculum. It was strategically designed in a stepwise fashion to increase in depth and difficulty as the program progressed. Thus, participants were introduced to more difficult concepts after more basic foundational information was provided. Additionally, classes could not be missed. As a result, growers were exposed to the entire curriculum for the online program. There is also a substantial administrative advantage to not having to approve or deny excused absences from class.

A significant benefit with online programs is that participants can listen to the modules as many times as needed to reinforce the content. If a participant missed what a speaker says in a traditional live program, they may have lost the opportunity to gain the information. The logical recourse would be to ask the speaker to repeat the information or ask a classmate or the coordinator for help. However, participants in a master producer program are fettered by the class being composed of competing nurseries. Also, a participant may not even realize they did not understand a particular point until after class is over. With the asynchronous online program, participants can listen to and watch the modules as many times as needed to master a difficult concept. In the case of the TMNP, students often reviewed modules such as irrigation, economics/marketing, or weed management three or four times or more before completing the posttest. If questions remain, the participants can privately ask the program coordinator online or by phone. In a live classroom, participants with some hearing loss (but not technically impaired) or those who are easily distracted by neighboring conversation may only have the option of moving toward the front or near the audio speaker, which may not fully address their needs. In an asynchronous program, students can control their learning environment, audio volume, and likewise, can control the monitor display size to optimize their learning experience.

There are numerous advantages and disadvantages for online asynchronous delivery. Program content, initial budget, audience demographic and location (and possibly preference), and available IT resources should be considered. The ability to interact with national specialists and have them address specific concerns or questions is a significant advantage of traditional programming, as is the flexibility to quickly change the topic or the focus of any one presentation based on the latest industry or research developments. Although there are advantages of having face-to-face interaction with specialists, this benefit will require a significant travel budget. There is also the possibility of scheduling conflicts with speakers which could lead to inconsistencies in content.

Although initial costs and time needed for online program development can be high, some of the biggest advantages of developing an online asynchronous program are the ability of the audience to access the information when it is convenient and view it as many times as needed to master the 
concept without travel time or expense, the potential for tremendous economies of scale, and the flexibility and time savings afforded instructors. Development of the online TMNP took $6.5 \times$ longer and significantly greater upfront costs than the traditional live program (Marble et al., 2016). However, overall costs of the online program are expected to be much less on a per student basis as more growers participate in the program. As no travel was involved with the online version, program participants saved an average of $\$ 152$ in travel costs, which reduced the overall cost to participate by $45 \%$ and over $6 \mathrm{~h}$ of travel time. This also eliminated the need to reserve funding for speaker travel. Future costs for the online version of TMNP include ongoing website maintenance and program content will need to be periodically revised or updated depending on subject matter and emerging industry issues. There will likely be a greater lag time between literature on an emerging issue becoming available and incorporating the new information into an online module than updating a live presentation.

The primary goal of any extension program is to disseminate information and foster new skills and practices, ultimately leading to economic savings. The online asynchronous TMNP accomplished this goal by providing content in a stepwise fashion, progressively increasing in depth and difficulty for each subject, and by affording participants the ability to view any module as many times as needed, often three times or more, until a particular subject was mastered. These attributes likely contributed to the difference in reported economic impact for program participants taking the online version and the traditional program. Compared to real-time face-to-face instruction and peer-to-peer learning, online instruction offers a newer approach for extension personnel to complete the extension mission of teaching their audience cost-effectively, especially for information that is routinely presented to large audiences; reduces the ongoing time commitment required of both instructors and program participants; and provides program organizers with the ability to instantaneously capture data on grower needs, educational achievement, program impacts, and other desired information.

\section{Literature cited}

Bohlen, J., C.M. Coughenour, H.F. Lionberger, E.O. Moe, and E.M. Rogers. 1960. Adopters of new farm ideas: Characteristics and communication behavior. North Central Reg. Ext. Publ. No. 13. 26 Nov. 2015. <http://www.soc.iastate.edu/ extension/pub/comm/NCRl3.pdf>.

Breneman, D.W. 2002. For colleges, this is not just another recession. Chron. High. Educ. 48:B7-B9. 19 Feb. 2016. <http://www.nyu.edu/classes/jepsen/ chronicleJun1402.pdf $>$.

Floyd, A. 2014. Facing budget cuts, extension worked to find local priorities. 19 Feb. 2016. <http://growinggeorgia.com/ features /2014/04/facing-budget-cutsextension-worked-find-local-priorities $/>$.

Jones, R., A. Goheen, K. Dhuyvetter, T. Kastens, and V. Amanor-Boadu. 2007. Using distance education in extension programming. J. Agr. Appl. Econ. 39:265274.

Marble, S.C., A. Fulcher, and R. Karel. 2016. Developing an asynchronous online Tennessee master nursery producer program. HortTechnology 26:575-583.

Payne, J.M. 2004. Views on federal formula funds Smith-Lever 3 (b) \& (c) and 3 (d) line items. Utah State University Extension March 2004 survey. 29 Aug. 2016. <http://escop.ncsu.edu/infobook/ ExtensionMarch2004Survey.pdf>.

Potter, W. 2003. State lawmakers again cut higher education spending. Chron. High. Educ. 49:A22. 19 Feb. 2016. <http:// archive.sheeo.org/about/press/ APPROP/Chronicle_8-8-03.pdf>.

Richards, J., C. Oreatt, G.J. Skolits, and J. Burney. 2012. Developing and evaluating the impact of an extension-based trainthe-trainer model for effectively disseminating food safety education to middle school students. J. Ext. 50:4. 10 Apr. 2016. <http://www.joe.org/joe/2012august/ a6.php>.

Serenari, C., M.N. Peterson, R.E. Bardon, and R.D. Brown. 2013. The impacts of the Great Recession on state natural resource extension programs. J. Ext. 51:4. 19 Feb. 2016. <http://www.joe.org/joe/ 2013august/all.php>.

The Engaged Institution. 1999. The third report: Returning to our roots. Kellogg Commission on the future of state and land grant universities. 10 Apr. 2016. <http:// www.aplu.org/library/returning-to-ourroots-the-engaged-institution/file $>$.

Wang, S.L. 2014. Cooperative Extension System: Trends and economic impacts on U.S. agriculture. Choices Quarter 1. 7 Mar. 2016. <http://www.choicesmagazine. org/UserFiles/file/cmsarticle_355.pdf>.

Warner, L.A., A. Harder, T. Wichman, and F. Dowdle. 2014. Increasing efficiency in extension using the train-thetrainer approach. Univ. Florida Inst. Food Agr. Sci. Publ. AEC517. 7 Mar. 2016. $<$ https://edis.ifas.ufl.edu/pdffiles/WC/ WC17000.pdf>.

Wells, E. 2004. Use of technology by Cooperative Extension Agents: A review of the literature. CEP953. 7 Mar. 2016. $<$ https://www.msu.edu/ wellselz/ LiteratureReviewTechandExt.pdf>.

Zumeta, W. 2010. The great recession: Implications for higher education, p. 2942. In: H. Wechsler (ed.). The NEA 2010 almanac of higher education. Natl. Educ. Assn., Washington, DC. 